\title{
Developing a Procedure of Extracting Total Polysaccharide from Dendrobium Nobile Lindl. in Vietnam
}

Xây dựng quy trình chiết polysaccharide tổng số từ loài Dendrobium nobile Lindl. ở Việt Nam

\author{
Nguyen Thi Viet Thanh \\ Hanoi University of Science and Technology, Hanoi, Vietnam \\ Email: thanh.nguyenthiviet@hust.edu.vn
}

\begin{abstract}
Dendrobium nobile Lind., also known as Hoang thao dui ga, is a species of plant belonging to the genus Dendrobium, a large genus of the Orchidaceae. This is a medical plant used in many remedies in China and Vietnam. Polysaccharide from this species has been shown many valuable biological activities such as hypoglycemia antioxidant and anti-cancer. In this paper, a procedure for extracting total polysaccharide by aqueous solvent from D.nobile based on the survey of factors: temperature, time, material/solvent ratio affecting this extraction process was proposed. The total polysaccharide content was also determined according to phenol-sulfuric acid method.
\end{abstract}

Keywords: Dendrobium nobile Lindl, polysaccharide, phenol-sulfuric acid.

Tóm tắt

Dendrobium nobile Lindl. hay còn được gọi là Hoàng thảo đùi gà là một loài thực vật thuộc chi thạch hộc (Dendrobium), là một chi lớn trong họ Lan (Orchidaceae). Đây là một vị thuốc được sử dụng trong nhiều bài thuốc ở Trung Quốc và Việt Nam. Polysaccharide từ loài này đã được chứng minh có nhiều hoạt tính sinh học quý giá như hạ đường huyết, chống oxi hóa, chống ung thư. Trong bài báo này, chúng tôi đưa ra quy trình chiết polysaccharide tổng số bằng dung môi nước từ loài D. nobile dựa trên việc khảo sát những yếu tố ảnh hưởng: nhiệt độ chiết, thời gian chiết, tỉ lệ nguyên liệu/dung môi đến quá trình chiết này, đồng thời xác định được hàm lượng polysaccharide tổng số bằng phương pháp phenol- sulfuric acid.

Từ khóa: Dendrobium nobile Lindl., polysaccharide, phenol-sulfuric acid.

\section{Mở đầu}

Dendrobium nobile Lindl. còn gọi là hoàng thảo đùi gà, hoàng thảo cẳng gà là một trong những loài được sử dụng nhiều nhất trong trong những loài thuộc chi Dendrobium. Trong đông y. D.nobile có vị ngọt hơi nhạt, tính hơi lạnh có tác dụng dưỡng âm ích vị, sinh tân dung trong các bệnh sốt nóng, miệng khô, họng khô... D.nobile được dùng trong các bài thuốc Trung Quốc có tác dụng để bồi bổ, sinh dịch .... Các sản phẩm chức năng chiết xuất từ D.nobile được sử dụng cho người luyện tập thể thao trước khi luyện tập để tăng lực $[1,2]$.

D.nobile chứa nhiều các lớp chất như alkaloid, sesquiterpene, phenathrene và bibenzyl, polysaccharide ngoài ra còn chứa các acid hữu cơ. Đặc biệt cặn chiết polysaccharide tổng số đã chứng tỏ nhiều hoạt tính sinh học quý giá như hoạt tính chống ung thư trên các dòng tế bào Sarcoma 180, LH-60, hoạt tính chống oxi hóa thể hiện hoạt tính kháng gốc tự do tốt trên hệ $\mathrm{ABTS}$ và có khả năng kháng gốc tự do $\mathrm{OH}$ và hệ $\mathrm{DPPH}$ [3-6]. Với ưu điểm hòa tan tốt trong nước và độc tính thấp hơn các nhóm chất khác, polysacharite có khả năng dễ dàng hấp thu vào cơ thể. Hàm lượng polysaccharide khá lớn trong cây nên polysaccharide từ loài D.nobile là một lớp chất hứa hẹn nhiều triển vọng để phát triển các sản phẩm tự nhiên làm thực phẩm chức năng và làm thuốc điều trị. Tuy nhiên cho đến nay việc nghiên cứu về polysaccharide mới chỉ tập trung ở Trung Quốc. Trong bài báo này lần đầu tiên quy trình chiết xuất polysaccharide tổng từ loài D.nobile được xây dựng ở Việt Nam.

\section{Vật liệu và phương pháp nghiên cứu}

\subsection{Mẫu thục vật, hóa chất, thiết bị}

Mẫu Hoàng thảo đùi gà thu hái ở Quảng Bình và được TS. Bùi Văn Thanh (Viện Sinh thái và Tài nguyên Sinh vật-VAST) xác định tên khoa học loài Dendrobium nobile Lindl. thuộc chi thạch hộc Dendrobium, họ lan Orchidaceae. Mẫu được đặt tên $\mathrm{DN} 1$ và được lưu tại Viện sinh thái và tài nguyên sinh vật, VAST. Mẫu nghiên cứu loài $D$. nobile (cả cây) được thái nhỏ, sấy khô, nghiền nhỏ với kích thước cỡ $1 \mathrm{~mm}$ thu được bột nguyên liệu khô. 


\section{Hóa chất, thiết bị:}

Chất chuẩn: D-glucose - Merck, hóa chất tinh khiết: Sulfuric acid 98\%, phenol, petroether, ethanol, chloroform, buthanol - Trung Quốc

\section{Máy đo UV-VIS Agilent 8453}

\subsection{Phuơng pháp nghiên cúu}

\section{Phuoong pháp dịnh luọng polysaccharide}

Sử dụng phương pháp phenol-sulfuric acid [7]: Dựa vào phản ứng thuỷ phân polysaccharide thành monosaccharide, monosaccharide tạo màu với phenol trong môi trường acid, dung dịch tạo thành có độ hấp thụ cực đại tại bước sóng $\lambda=490 \mathrm{~nm}$. Xây dựng đường chuẩn mật độ quang $\mathrm{A}$ ở bước sóng $\lambda=490 \mathrm{~nm}$ của glucose đã tạo màu với phenol ở một dải nồng độ glucose có sẵn $0 ; 22,45 ; 67,5 ; 90 \mu \mathrm{g} / \mathrm{ml}$ thu được phương trình đường chuẩn:

$$
y=0.0066 x+0.2023
$$

trong đó:

$y$ : giá trị mật độ quang của mẫu đo ở bước sóng $\lambda=490 \mathrm{~nm}$.

$x$ : Nồng độ glucose $(\mu \mathrm{g} / \mathrm{ml})$

Cặn tổng polysaccharide được đem xác định hàm lượng polysaccharide

- Cân chính xác 0,005 gam mẫu hòa tan và định mức thành $10 \mathrm{ml}$ bằng nước cất, nồng độ là $1 \mathrm{mg} / \mathrm{ml}$ (10000 $\mu \mathrm{g} / \mathrm{ml})$.

- Lấy $0,75 \mathrm{ml}$ dung dịch trên pha thành $10 \mathrm{ml}$, nồng độ $75 \mu \mathrm{g} / \mathrm{ml}$.

- Lấy $1 \mathrm{ml}$ dung dịch trên cho vào ống nghiệm có nút đậy, thêm $1 \mathrm{ml}$ dung dịch phenol 5\%,5 ml $\mathrm{H}_{2} \mathrm{SO}_{4}$ đậm đặc, lắc đều ống nghiệm. Đặt ống nghiệm vào cốc nước sôi 2 phút rồi làm lạnh ở nhiệt độ phòng 30 phút.

- Đo mật độ quang của dung dịch này ở bước sóng $490 \mathrm{~nm}$. Dựa vào phương trình đường chuẩn, suy ra hàm lượng tổng polysaccharide.

Phuong pháp chiết xuất polysaccharide tổng số tù loài D.nobile

Polysaccharide tổng số được chiết bằng dung môi nước và kết tủa bằng ethanol $95 \%$, các tạp chất hữu cơ được loại bằng cách sử dụng các dụng môi hữu cơ petroether, ethanol $80 \%$, chloroform/buthanol. $[3,6,8]$.

\section{Bố trí thi nghiệm:}

$5 \mathrm{~g}$ bột D.nobile được đem chiết bằng $150 \mathrm{ml}$ petroleum ether ở $60{ }^{\circ} \mathrm{C}$ trong $2 \mathrm{~h}$. Dịch chiết được loại bỏ thu được phần bã nguyên liệu. Bã nguyên liệu sau đó được chiết với $150 \mathrm{ml}$ ethanol $80 \%$ trong 2 h.
Dịch chiết được loại bỏ thu được bã nguyên liệu. Hai giai đoạn chiết nêu trên nhằm loại bỏ tạp chất tan trong petroleum ether và tạp chất tan trong ethanol. Phần bã sau đó được chiết bằng dung môi nước để thu được polysaccharide tan trong nước. Dịch chiết thu được loại protein bằng chloroform/buthanol rồi cô bớt dung môi tới thể tích còn $1 / 3$ so với thể tích ban đầu. Sau đó dịch chiết được bổ sung ethanol $95 \%$ với tỷ lệ $3: 1(\mathrm{v} / \mathrm{v})$ và để lạnh ở $4{ }^{\circ} \mathrm{C}$ trong khoảng thời gian 24 giờ, khi đó polysaccharide sẽ kết tủa. Hỗn hợp được đem ly tâm trong khoảng 10 phút thu được cặn chiết polysaccharide. Cặn này được rửa bằng methanol và được làm đông khô thu được cặn chiết polysaccharide tổng. Trong các giai đoạn trên thì giai đoạn chiết polysaccharide trong nước ảnh hưởng lớn nhất tới hàm lượng polysaccharide. Do đó giai đoạn này được khảo sát theo các yếu tố ảnh hưởng:

- Ảnh hưởng của thời gian chiết: mẫu D.nobile được chiết trong dung môi nước theo tỉ lệ nguyên liệu/dung môi $1 / 30(\mathrm{mg} / \mathrm{ml})$, nhiệt độ $100{ }^{\circ} \mathrm{C}$ và được chiết trong các khoảng thời gian $1 \mathrm{~h}, 2 \mathrm{~h}, 3 \mathrm{~h}, 4 \mathrm{~h}, 5 \mathrm{~h}$.

- Ảnh hưởng của tỉ lệ nguyên liệu/dung môi: mẫu D.nobile được chiết trong theo tỉ lệ nguyên liệu/dung môi $1 / 25,1 / 30,1 / 35,1 / 40(\mathrm{mg} / \mathrm{ml})$, nhiệt độ $100^{\circ} \mathrm{C}$ và được chiết trong các khoảng thời gian $3 \mathrm{~h}$.

- Ảnh hưởng của nhiệt độ chiết: mẫu D.nobile được chiết trong dung môi nước theo tỉ lệ nguyên liệu/dung môi $1 / 30(\mathrm{mg} / \mathrm{ml})$, nhiệt độ $60^{\circ} \mathrm{C}, 70^{\circ} \mathrm{C}$, $80^{\circ} \mathrm{C}, 90^{\circ} \mathrm{C}, 100{ }^{\circ} \mathrm{C}$ và được chiết trong các khoảng thời gian $3 \mathrm{~h}$.

\section{Kết quả và thảo luận}

Kết quả khảo sát các yếu tố ảnh hưởng tới hàm lượng polysaccharide tổng số trong giai đoạn chiết polysaccharide trong nước như sau.

\subsection{Anh hưởng của thời gian chiết tới hàm lự̂ng polysaccharide}

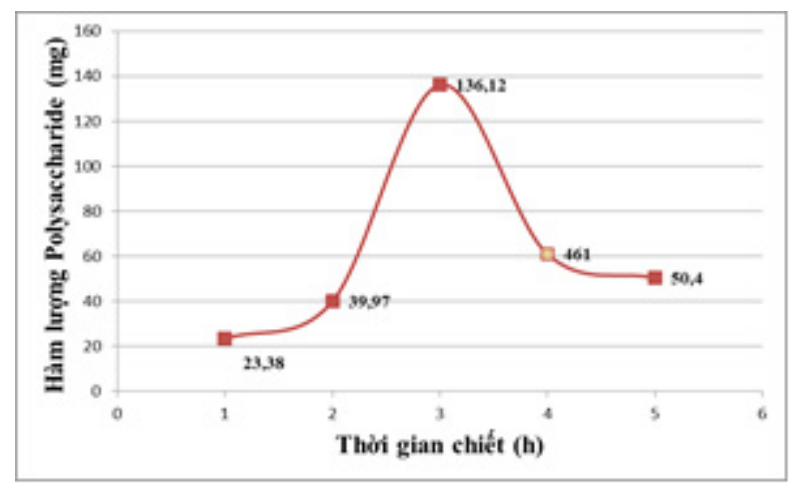

Hình 1. Đồ thị biểu diễn sự phụ thuộc của hàm lượng polysaccharide trong 5 mẫu nguyên liệu vào thời gian chiết 
Kết quả cho thấy hàm lượng polysaccharide đạt được cao nhất khi chiết trong khoàn thời gian $3 \mathrm{~h}$. Khi tăng thời gian chiết từ $1 \mathrm{~h}$ đến $3 \mathrm{~h}$ thì hàm lượng polysaccharide tăng nhanh chóng. Tuy nhiên, hàm lượng polysaccharide lại giảm đi sau khoảng thời gian chiết là $3 \mathrm{~h}$. Do đây là quá trình trích ly các phân tử chất tan nên thời gian trích ly kéo dài cũng làm tăng hàm lượng polysaccharide hòa tan cho đến khi đạt đến hàm lượng tối ưu. Tuy vậy sau $3 \mathrm{~h}$ thì hàm lượng polysaccharide sẽ không tăng. Theo các tác giả nghiên cứu quá trình chiết polysaccharide $[6,7,9]$, do quá trình chiết xuất hầu như đã xảy ra hoàn toàn và thời gian chiết xuất kéo dài có thể gây ra sự phân hủy các polysaccharide mạch ngắn có cấu trúc không bền vững và hậu quả có thể làm cho hàm lượng polysaccharide giảm.

\section{2. Ảnh hưởng của nhiệt độ chiết tới hàm luọng polysaccharide}

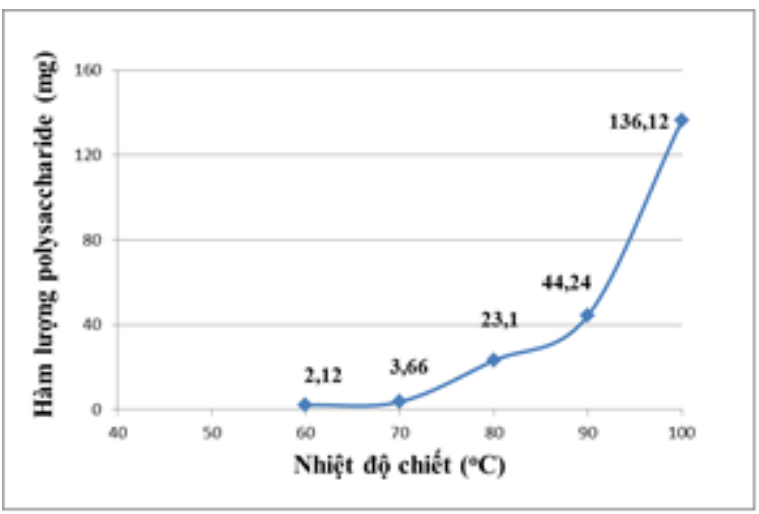

Hình 2. Đồ thị biểu diễn sự phụ thuộc của hàm lượng polysaccharide trong $5 \mathrm{~g}$ mẫu nguyên liệu vào nhiệt độ chiết
Kết quả cho thấy hàm lượng polysaccharide tăng có ý nghĩa thống kê trong khoảng nhiệt độ trích ly được thực hiện $\left(70^{\circ} \mathrm{C}\right.$ đến sôi $\left.\sim 100^{\circ} \mathrm{C}\right)$. Theo các tác giả Phạm Bảo Trương và Nguyễn Minh Thủy [9], ở nhiệt độ này đã xảy ra quá trình trích ly các phân tử polysaccharide hòa tan mà chủ yếu là polysaccharide peptide với khối lượng phân tử khoảng $5 \times 10^{5} \mathrm{Da}$. Phân tử polysaccharide peptide được cấu tạo từ các phân tử polysaccharide và các amino acid, trong đó phần polysaccharide bao gồm glucose, galactose, arabinose, xylose và mannose, các phân tử liên kết với nhau thông qua liên kết $\beta$-glucoside. Khoảng 17 loại axit amin liên kết với các phân tử polysaccharide. Chính các gốc acid amin có tính phân cực làm cho các phân tử hòa tan dễ dàng hơn khi tăng nhiệt độ.

\subsection{Anh hương của tỉ lệ nguyên liệu/dung môi vào hàm luọng polysaccharide}

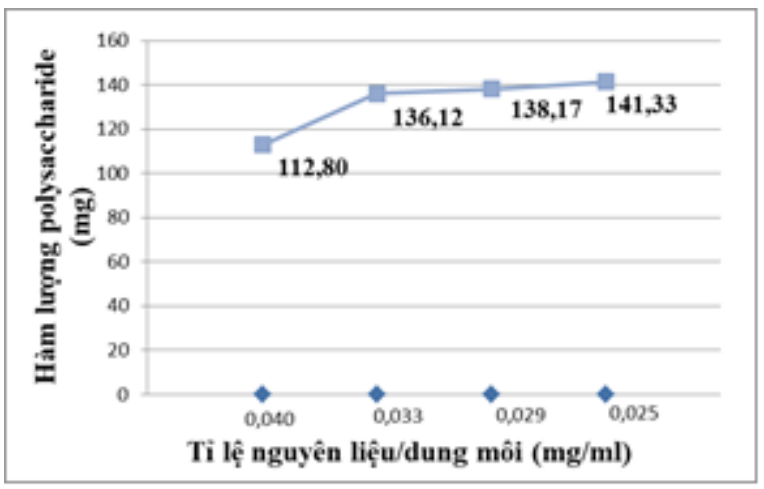

Hình 3. Đồ thị biểu diễn sự phụ thuộc của hàm lượng polysaccharide trong $5 \mathrm{~g}$ mẫu nguyên liệu vào tỉ lệ nguyên liệu/dung môi

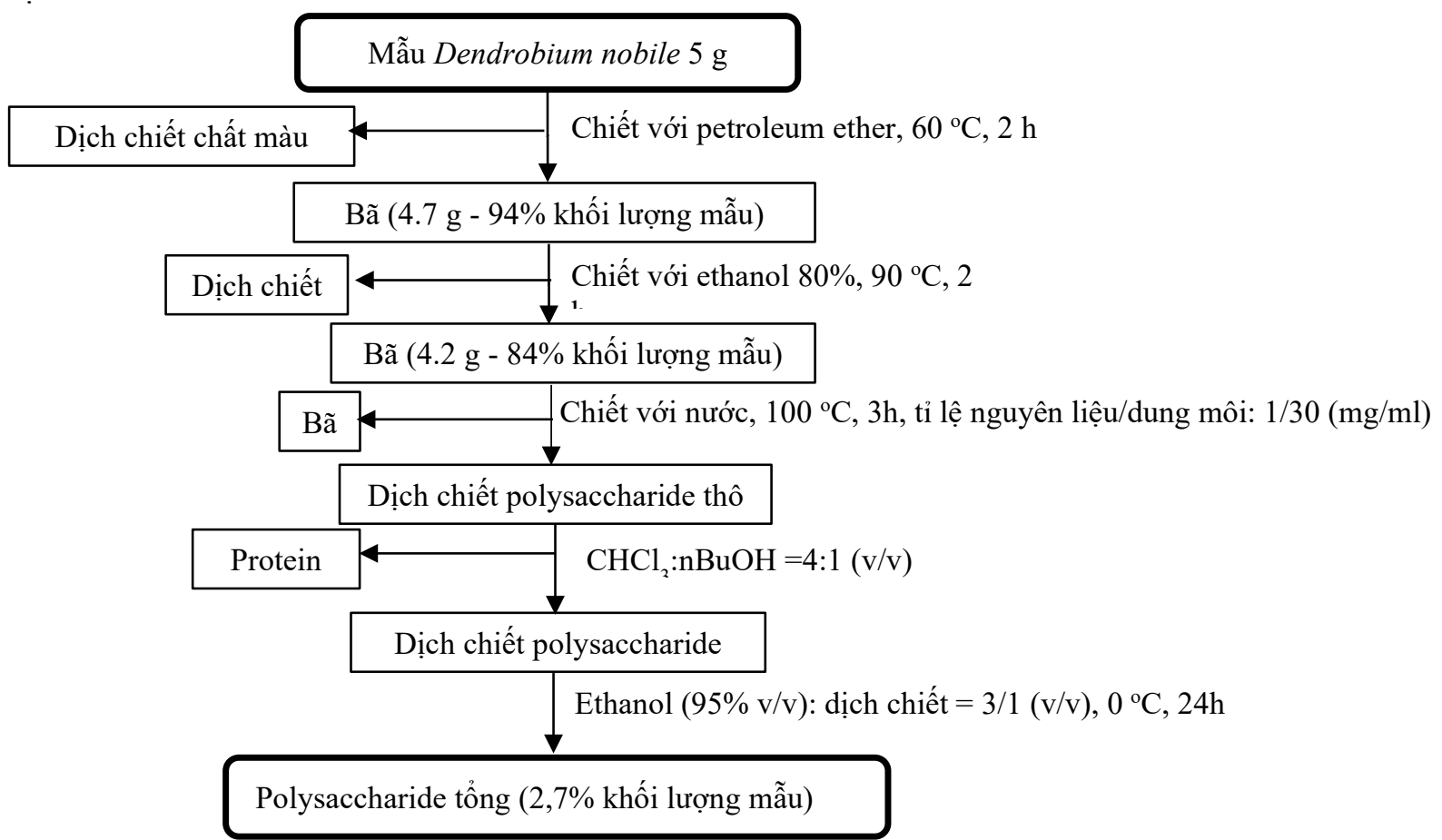

Hình 4. Quy trình chiết polysaccharide từ loài D.nobile 
Kết quả cho thấy khi lượng dung môi tăng lên thì khả năng hòa tan của các polysaccharide tăng lên. Nguyên nhân là khi tăng lượng dung môi lên so với lượng mẫu thì khả năng khuyếch tán của polysaccharide vào dung môi tăng lên do vậy hàm lượng polysaccharide thu được tăng lên. Tuy vậy khi tỉ lệ nguyên liệu/dung môi $>1 / 30(\mathrm{mg} / \mathrm{ml})$ thì hàm lượng polysaccharide thu được tăng rất ít. Do vậy để giảm chi phí về dung môi cũng như chi phí thực hiện quá trình chiết thì tỉ lệ nguyên liệu/dung môi tối ưu là $1 / 30(\mathrm{mg} / \mathrm{ml})$.

So sánh với quy trình chiết polysaccharide tổng số từ loài D.nobile ở Tứ Xuyên, Trung Quốc [10,11], giai đoạn chiết trong nước diễn ra trong thời gian ngắn hơn $\left(\right.$ ơ $^{\circ} 80^{\circ} \mathrm{C}$ và thời gian chiết $\left.2 \mathrm{~h}\right)$. Điều này có thể là do thành phần polysaccharide từ loài D.nobile ở Việt Nam có khối lượng phân tử lớn hơn và cấu trúc thẳng hơn dẫn tới khó tan trong nước hơn so với polysaccharide từ loài này ở Trung Quốc. Từ đó cho phép định hướng việc phân đoạn polysaccharide tổng số cho các bước nghiên cứu tiếp theo cấu trúc và hoạt tính sinh học của polysaccharide. Loài D.nobile đã ở Việt Nam có hàm lượng polysaccharide tổng số gần tương đương với hàm lượng polysaccharide của loài này ở Tứ Xuyên, Trung Quốc $(3,1 \%)$ [11]. Kết quả này cho thấy triển vọng trong việc nghiên cứu ứng dụng của polysaccharide, đặc biệt là nghiên cứu về hoạt tính sinh học của chiết phẩm polysaccharide thu được.

Từ những khảo sát về điều kiện chiết xuất polysaccharide cho phép đưa ra quy trình chiết polysaccharide ở quy mô phòng thí nghiệm như Hình 4.

\section{Kết luận}

Từ việc khảo sát ảnh hưởng của các điều kiện chiết polysaccharide cho phép xây dựng được quy trình chiết polysaccharide thích hợp trong dung môi nước ở nhiệt độ $100{ }^{\circ} \mathrm{C}$, thời gian chiết $3 \mathrm{~h}$, tỉ lệ nguyên liệu/dung môi: $1 / 30(\mathrm{mg} / \mathrm{ml})$. Ở điều kiện chiết này, hàm lượng polysaccharide thu được là 2.7\% (tính theo khối lượng mẫu khô). Hàm lượng polysaccharide của D.nobile ở Việt Nam tương đương với hàm lượng polysaccharide của D.nobile vùng Tứ Xuyên Trung Quốc (3,1\%) [11].

\section{Lời cảm ơn}

Công trình này là kết quả của đề tài $\mathrm{B} 2016$ BKA-11 được tài trợ bởi Bộ Giáo dục và Đào tạo.

\section{Tài liệu tham khảo}

[1] Đỗ Tất Lợi, Những cây thuốc và vị thuốc Việt Nam, trang 638, Nhà xuât bản Y học, 2004.
[2] Phạm Hoàng Hộ, Cây cỏ Việt Nam, tập 3, trang 821, Nhà xuất bản Trẻ, 2003.

[3] Xing, X., Cui, S. W., Nie, S., Phillips, G. O., Goff, H. D., \& Wang, Q., A review of isolation process, structural characteristics, and bioactivities of watersoluble polysaccharides from Dendrobium plants, Bioactive Carbohydrates and Dietary Fibre, 1(2), (2013), 131-147. https://doi.org/10.1016/j.bcdf.2013.04.001

[4] Yang, S., Gong, Q., Wu, Q., Li, F., Lu, Y., \& Shi, J., Alkaloids enriched extract from Dendrobium nobile Lindl. attenuates tau protein hyperphosphorylation and apoptosis induced by lipopolysaccharide in rat brain. Phytomedicine, 21(5), (2014). 712-716. https://doi.org/10.1016/j.phymed.2013.10.026

[5] Zhou, X., Zheng, C., Wu, J., Chen, G., Chen, J., \& Sun, C., Five new lactone derivatives from the stems of Dendrobium nobile. Fitoterapia, 115, (2016), 96100

https://doi.org/10.1016/j.fitote.2016.10.002

[6] AoXue Luo, XingJin He, Song, Dong Zhou, YiJun Fan, Tao He, Ze Chun, In vitro antioxidant activities of a water-soluble polysaccharide derived from Dendrobium nobile Lindl. extracts, International Journal of Biological Macromolecules, 45, (2009), 359-363.

https://doi.org/10.1016/j.ijbiomac.2009.07.008

[7] S. Sadasivam, A. Manickam, Biochemical methods, New Age International (P) Limited Publishers, New Delhi, Chapter 1, 10-11, 2005.

[8] Yanfei Peng, Baoqin Han,Wanshun Liu and Ruixue Zhou, Deproteinization and structural characterization of bioactive exopolysaccharides from Ganoderma sinense mycelium, Separation Science and Technology, 51(2), (2016), 359-369. https://doi.org/10.1080/01496395.2015.1086375

[9] Phạm Bảo Trương và Nguyễn Minh Thủy, Tối ưu hóa quá trình trích ly polysaccharide và tannin trong nấm linh chi đỏ (Ganoderma lucidum), Tạp chí Khoa học Trường Đại học Cần Thơ Phần B: Nông nghiệp, Thủy sản và Công nghệ Sinh học, 36, (2015), 21-28.

[10] Mark Q. Guo, Xinzhong Hu, Changlu Wang and Lianzhong $\mathrm{Ai}$, Solubility of polysaccharides, Chapter 2 Polysaccharides: structure and solubility, (2017), Intech, Croatia.

[11] Jun-Hui Wang, Xue-Qiang Zha, Jian-Ping Luo, XueFei Yang, An acetylated galactomannoglucan from the stems of Dendrobium nobile Lindl., Carbonhydrat Research 345, (2010), 1023-1027. https://doi.org/10.1016/j.carres.2010.03.005

[12] Jun-Hui Wang, Jian-Ping Luo, Xue-Qiang Zha, Structural features of a pectic polysaccharide from the stems of Dendrobium nobile Lindl., Carbohydrate Polymers $81,(2010), 1-7$.

https://doi.org/10.1016/j.carbpol.2010.01.040. 